Journal of Animal and Veterinary Advances 9 (24): 3083-3091, 2010

ISSN: $1680-5593$

(C) Medwell Journals, 2010

\title{
Novel Genotypes of Type 2 Porcine Circovirus (PCV2) in PMWS Pigs in China Between 2008 and 2009
}

\author{
${ }^{1}$ G.H. Zhao, ${ }^{1} \mathrm{~W}$. Cheng, ${ }^{2}$ P.J. Zhang, ${ }^{1}$ Y.S. Han and ${ }^{1}$ D.K. Chen \\ ${ }^{1}$ College of Veterinary Medicine, Northwest A and F University, \\ Yangling, 712100 Shaanxi Province, P.R. China \\ ${ }^{2}$ Department of Biology, Shaanxi Institute of Education, Xian, \\ 710061 Shaanxi province, P.R. China
}

\begin{abstract}
The present study analyzed genetic variation and genotypes of 17 strains of type 2 Porcine Circovirus (PCV2) from different epidemic regions in China in 2008 and 2009. All the genomic sequences were 1.767 bp in length. Sequence comparison of complete genomic sequences revealed 95.6-99.9\% identity among 17 PCV2 strains and the most variable regions within 1.000-1.700 nt (located in the coding region of ORF2). Comparative analysis of amino acids of the two ORFs revealed that variation extend of ORF2 (93.1-100\%) was greater than ORF1 (98.4-100\%) and the third codon position showed much more variable than the first and second sites. Mutations in $\mathrm{T}$ and $\mathrm{B}$ lymphocyte epitopes were also detected by comparative analysis and it was found that T lymphocyte epitopes were more conserved than those of B lymphocytes. Phylogenetic analysis revealed 6 novel genotypes of PCV2 in addition to the 5 known geneotypes (PCV-2a, PCV-2b, PCV-2c, PCV-2d, PCV-2e) reported. Of these genotypes, the PCV-2b, PCV-2d and 3 unidentified genotypes were the most prevailing, within 13,17 and 16 epidemic provinces, respectively. For the 17 Chinese PCV2 strains examined in this study, 5 strains represented PCV-2b genotype, 6 strains were PCV-2d, 1strain was PCV-2e and other 5 strains were novel genotypes while no strains were PCV-2a and PCV-2c genotype. These findings demonstrated the usefulness and attributes of complete genomic sequences for genetic variation and genotyping of PCV2 and have implications for the studies of population biology, molecular epidemiology and genetic structure of PCV2 and for the effective control of PMWS as well.
\end{abstract}

Key words: Genetic variation, genotype, PCV2, PMWS, epidemiology, China

\section{INTRODUCTION}

Porcine Circovirus (PCV), a non-enveloped virus with single-stranded and circular DNA (Jiang et al., 2010) was a member of the Circoviridae family (Lukert et al., 1995) and it can be classified into two types (PCV1 and 2) according to its antigenicity, pathogenicity and genomic difference (Allan et al., 1998; Morozov et al., 1998; Larochelle et al., 2002). PCV1 is considered nonpathogenic (Allan et al., 1994; Olvera et al., 2007) while PCV2 is described as the pivotal and primary causative agent of Postweaning Multisystemic Wasting Syndrome (PMWS) (Ellis et al., 1998; Fenaux et al., 2002, 2003; Ma et al., 2007; Shang et al., 2007; Li et al., 2010) and it also is associated with Porcine Dermatitis and Nephropathy Syndrome (PDNS), porcine reproductive disorders and other disease syndromes (Ladekjaer-Mikkelsen et al., 2001; Meehan et al., 2001; Segales et al., 2005; Shang et al., 2007).
PMWS is a newly emerging and economically important disease in pigs originally reported in Canada (Allan et al., 1998; Ellis et al., 1998; Allan and Ellis, 2000; Wen et al., 2005; Stevenson et al., 2007). It has been acknowledged in many European countries, some Asian countries and the US (Wen et al., 2005; Liu et al., 2007; Stevenson et al., 2007). Typically, clinical PMWS associated with PCV2 affects pigs from 5-12 weeks old (Wen et al., 2005; Jiang et al., 2010) with 5-50\% morbidity and nearly $100 \%$ mortality (Morozov et al., 1998; Shen et al., 2009; Jiang et al., 2010). Clinical signs of the disease include pallor, fever, jaundice and progressive weight loss, together with respiratory and digestive disorders (Clark, 1997; Liu et al., 2007; Olvera et al., 2007; Shen et al., 2009). It can also be pathologically characterized by lymphocyte depletion and granulomatous inflammation of lymphoid tissues (Rosell et al., 1999; Olvera et al., 2007). Now a days,

Corresponding Author: D.K. Chen, College of Veterinary Medicine, Northwest A and F University, 1 Xinong Road, The Yangling Agricultural Hi-tech Industries Demonstration Zone, Yangling, 712100 Shaanxi Province, The People's Republic of China 
PMWS has caused great concern throughout the swine industry because of its rapid, Simultaneous and worldwide emergence as well as the uncertain transmission mode and high mortality rates in pigs (Jiang et al., 2010).

Based on nucleotide or protein sequences of the complete genome or single (or combined) gene, phylogenetic and evolutionary studies are of increasing importance in molecular epidemiological studies on viral and bacterial pathogens (Jiang et al., 2010). The genome of PCV2 contains 1.767-1.768 Nucleotides (nt) which comprise 6 Open Reading Frames (ORFs) encoding putative proteins (Meehan et al., 1998; Stevenson et al., 2007). However, only 3 proteins encoded by ORF1, ORF2 and ORF3 have been detected mainly in PCV2 infected cells (Cheung, 2003). Among them, ORF1 encodes 2 replication associated proteins (Rep and Rep) (Mankertz et al., 1998; Cheung, 2003; Shang et al., 2007), ORF2 encodes a viral Capsid Protein (Cap) which is involved in the host immune responses (Meehan et al., 1998; Mahe et al., 2000; Nawagitgul et al., 2000; Shang et al., 2007).

Previous studies indicated that the PCV2 was a kind of multi-genotype virus based on the ORF2 and the whole genomic sequences as well (Larochelle et al., 2002; Olvera et al., 2007) which would increase viral complexity in the PMWS pigs in different epidemic regions or eras (Shuai et al., 2007; Segales et al., 2008; Wang et al., 2009).

To monitor the latest genotypic variation of PCV2 in PMWS pigs in China, especially in the high-production provinces, 17 PCV2 strains were collected from 11 epidemic provinces in China in 2008 and 2009. The present study described the complete genomic sequence analysis of these 17 PCV2 strains including their genetic variations and genotypes.

\section{MATERIALS AND METHODS}

Field samples and DNA preparation: From January 2008 to December 2009, clinical samples (lungs, lymph nodes, tonsil, livers and spleens) of pigs presenting clinical signs and lesions associated with PMWS were collected from different farms of 11 provinces in China. PCR and histopathologic analysis were used to confirm the samples and the PCV2 positive samples were used for genome amplification.

Representative PCV2 stains with detailed information including the designation, date of isolation, geographic origin, genome size, GenBank ${ }^{\mathrm{TM}}$ accession number are shown in Table 1.

For tissue samples, homogenates comprising 1:5 tissue/Phosphate Buffer Saline (PBS) were obtained after grinding in a glass homogenizer and were disrupted by freeze-thawing three times. The supernatants containing viruses were recovered by centrifugation and then were treated using penicillin and streptomycin and filter $(0.22 \mu \mathrm{m})$. The final solutions were added to the cell monolayer of $\mathrm{PK}-15$ cells for $1.5-2 \mathrm{~h}$ infection at $37^{\circ} \mathrm{C}$ and then discarded the infection solution and added maintenance media to culture the PCV2 virus. After 3-5 blind passages, the supernatants of cultural cells were used to extract total viral DNA with DNAZol extraction kit (Invitrogen) according to the manufacturer's recommendations. RNA was removed with the RNAase treatment step of the kit. DNA was recovered with centrifugation and then it was dried and dissolved in sterile water.

Enzymatic amplification and sequencing: The complete genome of PCV2 was amplified with primers P1 (-CCGggatccCCGCGGGCTGGCTGAACTTTTAAAAGT-3)

Table 1: PCV2 strains sequenced in the present study

\begin{tabular}{|c|c|c|c|}
\hline Designation & Geographic origin & Date of the isolation (Month/Year) & GenBank $^{\mathrm{TM}}$ accession number \\
\hline FJ-3 & Fujian (Qiuhui) & $4 / 2009$ & HM776437 \\
\hline FJ-4 & Fujian (Qiuhui) & $4 / 2009$ & HM776438 \\
\hline HLJ-7 & Heilongjian & $11 / 2008$ & HM776439 \\
\hline HLJ-10 & Heilongjian & $11 / 2008$ & HM776440 \\
\hline HUB-5 & Hubei (Wuhan) & $3 / 2009$ & HM776441 \\
\hline HUN-2 & Hunan (Loudi) & $6 / 2009$ & HM776442 \\
\hline HUN-11 & Hunan (Changsha) & $5 / 2009$ & HM776443 \\
\hline HUN & Hunan (Changde) & $5 / 2009$ & HM776444 \\
\hline JX-1 & Jiangxi (Xinjian) & $4 / 2008$ & HM776445 \\
\hline$J X-2$ & Jiangxi (Xinjian) & $4 / 2008$ & HM776446 \\
\hline LN-3 & Liaoning (Anshan) & $5 / 2009$ & $\mathrm{HM} 776447$ \\
\hline LN-19 & Liaoning (Anshan) & $5 / 2009$ & HM776448 \\
\hline $\mathrm{SC}-10$ & Sichuan (Leshan) & $3 / 2009$ & HM776449 \\
\hline SD & Shandong & $4 / 2009$ & $\mathrm{HM} 776450$ \\
\hline SX-1 & Shaanxi & $3 / 2009$ & HM776451 \\
\hline $\mathrm{YN}-8$ & Yunnan (Kunming) & $5 / 2009$ & HM776452 \\
\hline ZJ-38 & Zhejiang & $11 / 2008$ & HM776453 \\
\hline
\end{tabular}


J. Anim. Vet. Adv., 9 (24): 3083-3091, 2010

Table 2: Genome sequences of PCV2 strains deposited in the GenBank

\begin{tabular}{|c|c|c|c|c|c|}
\hline Designation $\quad \mathrm{C}$ & Geographic origin & Year of the isolation & Genome size (nt) & GenBank $^{\mathrm{TM}}$ accession number & Reference \\
\hline $\mathrm{J} 0955 \mathrm{~b}$ & Zhejiang & 2009 & 1767 & GU450329 & Unpublished \\
\hline GXWM & Guangxi & Unknown & 1767 & $\mathrm{EF} 675241$ & Unpublished \\
\hline HBsy-21 & Hubei & 2008 & 1767 & FJ870972 & Unpublished \\
\hline HZ08 & Zhejiang & 2008 & 1767 & FJ644927 & Li et al. (2010) \\
\hline SD-1 & Shandong & Unknown & 1767 & AY556473 & Unpublished \\
\hline TJ06 & Tianjin & 2006 & 1767 & EF524539 & Wang et al. (2009) \\
\hline CG08 & Shanghai & 2008 & 1767 & FJ644931 & Li et al. $(2010)$ \\
\hline GXHZ-1 & Guangxi & Unknown & 1767 & $\mathrm{EF} 675230$ & Unpublished \\
\hline $\mathrm{CHL}$ & Guangdong & Unknown & 1767 & AY682991 & Unpublished \\
\hline GL08 & Jiangsu & 2008 & 1767 & FJ644929 & Li et al. (2010) \\
\hline ZJjh-s & Zhejiang & 2008 & 1767 & FJ870970 & Unpublished \\
\hline HBwh-24 & Hubei & 2008 & 1767 & FJ870971 & Unpublished \\
\hline $\mathrm{JZ}$ & Shandong & Unknown & 1767 & DQ206444 & Unpublished \\
\hline TW & Taiwan & Unknown & 1768 & AF166528 & Unpublished \\
\hline MLTW98 & Taiwan & Unknown & 1768 & AF154679 & Unpublished \\
\hline Zhejiang2006 & Zhejiang & Unknown & 1767 & $\mathrm{EF} 210106$ & Unpublished \\
\hline CHST & Guangdong & Unknown & 1767 & AY682992 & Unpublished \\
\hline BJ0602 & Beijing & 2006 & 1768 & EF524540 & Wang et al. (2009) \\
\hline HB0603 & Hebei & 2006 & 1768 & EF524538 & Wang et al. (2009) \\
\hline FJ & Fujian & Unknown & 1768 & AY556474 & Unpublished \\
\hline GXGG-2 & Guangxi & Unknown & 1768 & EF675229 & Unpublished \\
\hline HN0601 & Henan & 2006 & 1768 & EF524531 & Unpublished \\
\hline LN05 & Liaoning & 2005 & 1767 & EF524526 & Wang et al. (2009) \\
\hline $\mathrm{HB} 0602$ & Hebei & 2006 & 1768 & EF524537 & Wang et al. (2009) \\
\hline WX06 & Shanghai & 2006 & 1767 & FJ644926 & Li et al. $(2010)$ \\
\hline GXHK & Guangxi & Unknown & 1767 & EF675238 & Unpublished \\
\hline $\mathrm{HNyz}-3 \mathrm{~b}$ & Henan & 2008 & 1767 & FJ870976 & Unpublished \\
\hline QY & Guangdong & Unknown & 1767 & AY682995 & Unpublished \\
\hline SH0822 & Shanghai & 2008 & 1767 & GU450330 & Unpublished \\
\hline BJW & Beijing & 2005 & 1767 & AY 847748 & Liu et al. (2007) \\
\hline GSLZ & Gansu & Unknown & 1767 & FJ447482 & Unpublished \\
\hline DQ08 & Zhejiang & 2008 & 1767 & FJ644928 & Li et al. $(2010)$ \\
\hline CQ08 & Chongqing & 2008 & 1767 & FJ608544 & Wang et al. (2009) \\
\hline $\mathrm{GX}$ & Guangxi & Unknown & 1767 & AY556475 & Unpublished \\
\hline $\mathrm{SC0} 7$ & Sichuan & 2007 & 1767 & FJ608538 & Wang et al. (2009) \\
\hline JX0601 & Jiangxi & 2006 & 1767 & EF524535 & Wang et al. (2009) \\
\hline SD-2 & Shandong & 2002 & 1767 & AY181947 & Wang et al. (2009) \\
\hline HaiNan & Hainan & Unknown & 1767 & AY556476 & Unpublished \\
\hline SDrc-1b & Shandong & 2008 & 1767 & FJ870975 & Unpublished \\
\hline ShenZhen & Shenzhen & 2008 & 1767 & FJ870969 & Unpublished \\
\hline HKS03-04 & Hongk ong & 2004 & 1767 & DQ997816 & Ma et al. (2007) \\
\hline HKS091-04 & Hongk ong & 2004 & 1767 & DQ997817 & Ma et al. (2007) \\
\hline HEN0901 & Henan & 2009 & 1767 & GU450328 & Unpublished \\
\hline AH0901 & Anhui & 2009 & 1767 & GU450327 & Unpublished \\
\hline HuB08 & Hubei & 2008 & 1767 & FJ608542 & Wang et al. (2009) \\
\hline GXIC & Guangxi & Unknown & 1767 & $\mathrm{EF} 675240$ & Unpublished \\
\hline HuNan & Hunan & Unknown & 1767 & AY556477 & Unpublished \\
\hline GY06 & Jiangsu & 2006 & 1767 & FJ644921 & Li et al. (2010) \\
\hline JXI & Jiangxi & Unknown & 1767 & AY686762 & Unpublished \\
\hline ZJ0401 & Zhejiang & 2004 & 1767 & EF524521 & Wang et al. (2009) \\
\hline TJ04 & Tianjin & 2004 & 1767 & EF524520 & Wang et al. (2009) \\
\hline GS04 & Gansu & 2004 & 1767 & EF524517 & Wang et al. (2009) \\
\hline SX04 & Shanxi & 2004 & 1768 & EF524523 & Wang et al. (2009) \\
\hline $\mathrm{ZC}$ & Guangdong & Unknown & 1767 & AY682997 & Unpublished \\
\hline SX04New & Shanxi & Unknown & 1767 & AY 604430 & Unpublished \\
\hline $\mathrm{HB} 0702$ & Hebei & 2007 & 1767 & FJ608541 & Wang et al. (2009) \\
\hline SH1 & Shanghai & 2002 & 1767 & FJ644919 & Li et al. $(2010)$ \\
\hline BJ0401 & Beijing & 2004 & 1767 & EF524515 & Wang et al. (2009) \\
\hline НТ06 & Shanghai & 2006 & 1767 & FJ644925 & Li et al. $(2010)$ \\
\hline SD05 & Shandong & 2005 & 1767 & FJ644563 & Zhao et al. (2009a) \\
\hline QZ05 & Fujian & 2005 & 1767 & FJ644562 & Zhao et al. (2009b) \\
\hline Stoon- 1010 & Canada & Unknown & 1768 & AF055392 & Meehan et al. (1998) \\
\hline 48285 & France & Unknown & 1767 & AF055394 & Meehan et al. (1998) \\
\hline DK1980 PMWSfree & Denmark & Unknown & 1767 & EU148503 & Dupont et al. (2008) \\
\hline TJ & Tianjin & 2002 & 1767 & AY181946 & Wang et al. (2009) \\
\hline GX0601 & Guangxi & 2006 & 1768 & EF524532 & Wang et al. (2009) \\
\hline
\end{tabular}

and P2 (5-CAT ctcg ag ACCCGCGG AAA TTTCT GA CAAACGTTACA-3). The primer pairs were designed using software Oligo (Version 6.0) according to the published sequences of PCV2 in the GenBank ${ }^{\mathrm{TM}}$ (Table 2). PCR mix $(25 \mu \mathrm{L})$ included $2.5 \mu \mathrm{M}$ of each primer, $2.5 \mu \mathrm{L}$ of $10 \times$ rTaq buffer, $0.2 \mathrm{mM}$ of each dNTP, $1.25 \mathrm{U}$ of rTaq DNA 
polymerase (TAKARA) and $1 \mu \mathrm{L}$ of DNA sample in a thermocycler (Biometra). The PCR was performed with the following conditions: an initial denaturation at $94^{\circ} \mathrm{C}$ for 35 min, followed by $94^{\circ} \mathrm{C}$ for $1 \mathrm{~min}$ (denaturation); $54^{\circ} \mathrm{C}$ for $1 \mathrm{~min}$ (annealing); $72^{\circ} \mathrm{C}$ for $1.5 \mathrm{~min}$ (extension) for 35 cycles then with a final extension at $72^{\circ} \mathrm{C}$ for $10 \mathrm{~min}$. These optimized cycling conditions for the specific and efficient amplification of individual DNA fragments were obtained after varying annealing temperatures). Samples without genomic DNA (no-DNA controls) or with host genomic DNA (host-DNA controls) were included in each amplification run and in no case were amplicons detected in the no-DNA and host-DNA controls. Each amplicon $(5 \mu \mathrm{L})$ was examined by agarose gel electrophoresis to validate amplification efficiency (Zhao et al., 2009a, b).

The PCR products were purified using spin columns (WizardTM PCR-Preps DNA Purification System, Promega) and ligated with pGEM-T Easy plasmid vector (Promega) according to the manufacturer's recommendations. The recombinant plasmid was then transformed into Escherichia coli DH5 $\alpha$ competent cells (Promega) and positive transformants were selected and checked by PCR amplification. Cell cultures with confirmed recombinant plasmid were cultured and sent to Songon Co. Ltd. (Shanghai) for sequencing. For each sample, 3 colonies were sequenced from both ends.

Molecular genetic analysis: Sequences of the complete genome were aligned using the Clustal X 1.81 (Thompson et al., 1997) and mVISTA (http://genome.lbl. gov/vista/mvista/submit.shtml). Alignments were checked by eye and modifications were made as required. Megalign procedure within the DNAStar 5.0 (Burland, 2000) was used to analyze sequence identity and to calculate base composition and the divergence. The Neighbor-Joining (NJ) method in Mega version 4.0 (Tamura et al., 2007) was used to examine the genetic relationship under default settings. The consensus tree was obtained after bootstrap analysis, with 1,000 replications and with values above $50 \%$ reported. We divided PCV2 genotypes with the following criteria as described by previous studies (Segales et al., 2008; Wang et al., 2009): when the ORF2 genetic distance between them is $>0.035$ and agrees with the distance between viral sequence groups in the phylogenetic trees revealed by complete genomic sequences, the two PCV2 genotypes are regarded as different. Phylograms were drawn using the Tree View program version 1.65 (Page, 1996).

\section{RESULTS AND DISCUSSION}

Sequence analysis of nucleotide and amino acid: Genomic DNA was prepared from 17 stains in 11 epidemic provinces of China. The complete genomes were amplified successfully from all of the samples. The amplicons were subjected to agarose gel electrophoresis, sequenced and then deposited into the GenBank ${ }^{\mathrm{TM}}$ with accession numbers HM776437-HM776453 (Table 1). No size variation was detected in all of the genomic sequences which were $1.767 \mathrm{bp}$ in length. The $\mathrm{A}+\mathrm{T}$ contents of complete genomic sequences were $51.10-51.78 \%$, slight higher than $\mathrm{G}+\mathrm{C}$ contents. All the complete genomic sequences of PCV2 in the present study contained at least six Open Reading Frames (ORFs), encoding 2 major proteins (Rep and Cap) as previous studies reported (Shang et al., 2007; Wang et al., 2009). The comparison of complete genomic sequences revealed 95.6-99.9\% identity in the $17 \mathrm{PCV}$ strains and the most variable regions were within 1.000-1.700 nt (located in the coding region of ORF2) (Fig. 1) which was consistent with previous study in China (Wang et al., 2009). Among these viruses, ZJ-38 and $\mathrm{HLJ}-10$ showed the highest identity with a percentage nearly to $100 \%$. Comparative analysis of amino acids of the two ORFs revealed that the variation extend of ORF2 (93.1-100\%) was greater than ORF1 (98.4-100\%) and the third codon position showed more variable than the first and second sites.

To date, at least 6 linear immunodominant regions and 5 overlapping conformational B lymphocyte epitopes within 47-85, 156-202 and 230-233 residues in the PCV2 Cap were revealed by PEPSCAN analysis and mAbs scanning (Mahe et al., 2000; Shang et al., 2007; Lekcharoensuk et al., 2004). Previous study also showed that 2 immunodominant regions encoded by PCV2 ORF1 (amino acid residues 81-100 and 201-220) and 1 region encoded by PCV2 ORF3 (amino acid residues 31-50) appeared to be able to induce $\mathrm{T}$ lymphocyte proliferation in porcine Peripheral Blood Mononuclear Cells (PBMCs) from infected pigs (Stevenson et al., 2007). It suggested that the $\mathrm{T}$ lymphocytes responses to $\mathrm{PCV} 2$ are primarily directed toward epitopes of the nonstructural proteins of ORF1 and ORF3. Comparative analysis of these regions detected 13 mutations (Table 3 ) in ORF2, 2 in ORF1 and 1 in ORF3 and T lymphocyte epitopes were more conserved than those of B lymphocytes (Table 3).

Phylogenetic relationships among PCV2 sequences: The NJ phylogenetic tree of the 17 Chinese PCV2 strains sequenced in the present study, together with 66 PCV2 


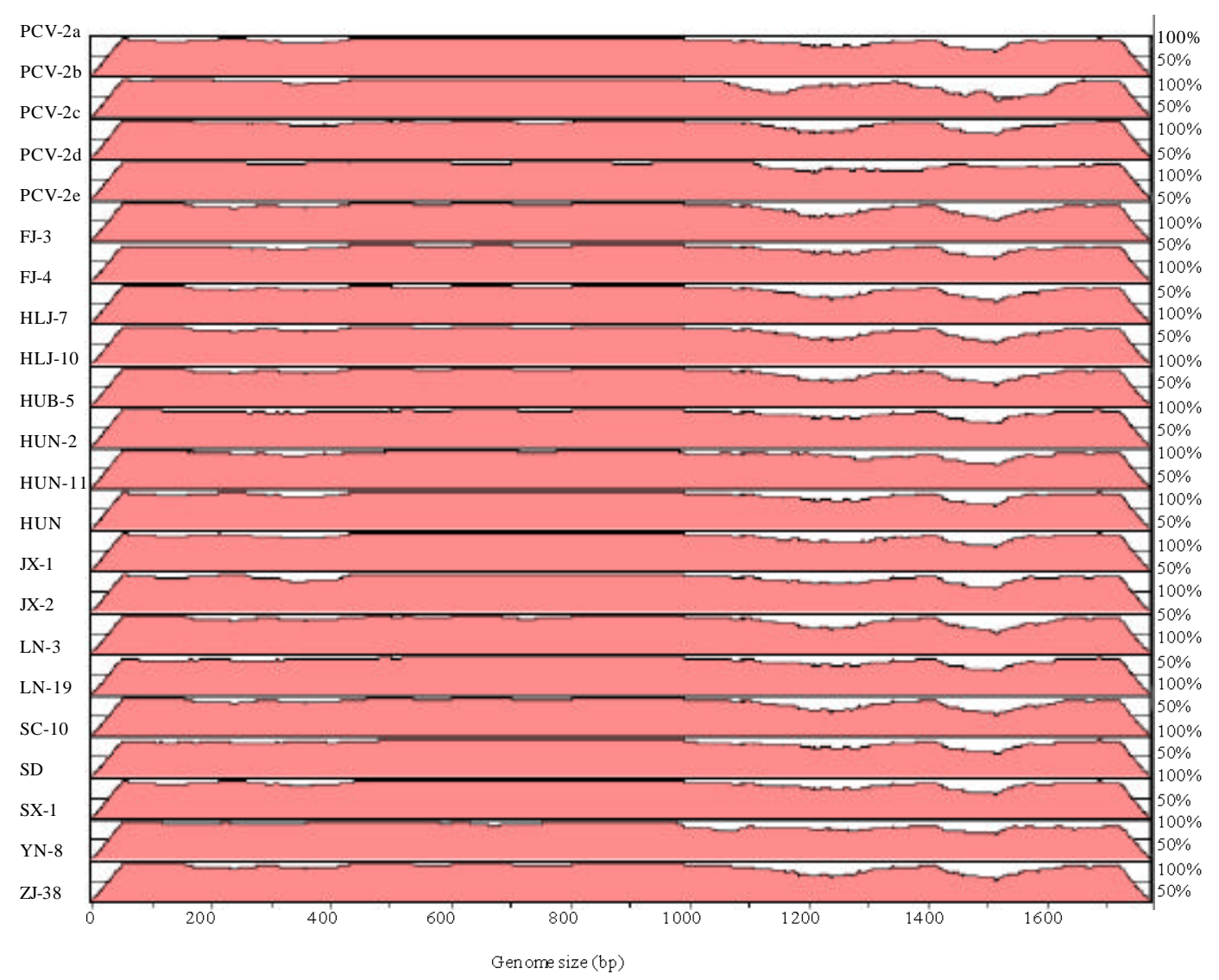

Fig. 1: Comparative analysis of complete genomic sequences of PCV2 in China using mVISTA

Table 3: Mutations in the sequences of $\mathrm{T}$ and $\mathrm{B}$ lymphocyte epitopes of $\mathrm{PCV} 2$

\section{Epitope}

region (aa) Mutation sites

47-85 47 (T-A), 53 (F-I), 57 (V-I), 59 (R-K-A), 63 (R-K-T), 68 (A-N)

$165-200168$ (S-R), 175 (P-R), 185 (L-M), 190 (A-T-S), 191 (G-A)

$231-233 \quad 232(\mathrm{~N}-\mathrm{H}), 233(\mathrm{P}-\mathrm{T})$

strains available in the GenBank ${ }^{\mathrm{TM}}$ (Table 2) with complete genomic nucleotide sequences, are shown in Fig. 2. All of these Chinese PCV2 strains were isolated from 25 epidemic provinces, respectively. Phylogenetic analysis showed 6 novel genotypes of PCV2 in addition to the 5 known geneotypes (PCV-2a, PCV-2b, PCV-2c, PCV-2d, PCV-2e) reported (Segales et al., 2008; Wang et al., 2009). The sequences were segregated into two large groups A and $\mathrm{B}$. The upper part of the tree contained 2 genotypes (PCV-2d and PCV-2b) in previous studies and 2 novel genotypes (unidentified type 2 and 3 ).

Three genotypes (PCV-2a, PCV-2c, PCV-2e) with 3 novel genotypes were in the other clade. Of these genotypes, PCV-2b, PCV-2d and the 3 unidentified genotypes were the most prevailing, within 13,17 and 16 epidemic provinces, respectively (Table 4). For the Chinese PCV2 strains in this study, 5 strains were in
PCV-2b, 6 strains were in PCV-2d, 1 strains in PCV-2e and other 5 strains were in novel genotypes but no strains were in genotypes of PCV-2a and PCV-2c (Fig. 2).

The study of the evolution of the genetic diversity of virus strains and the existence of variants are very important. It provides a better understanding of the pathogenesis of these potentially emerging diseases and has implications for the development of prophylactic measures (Larochelle et al., 2002). On the other hand, point mutation and recombination are major mechanism of viral evolution (Ma et al., 2007).

In the present study, complete genomes of 17 PCV2 strains in 11 epidemic provinces were sequenced and analyzed. The sequences contained at least $6 \mathrm{ORFs}$ and it was found that the Cap protein encoded by ORF 2 was the most variable regions and it exhibited a higher rate of variation (the lowest homology reported being 90\%) compared with ORF1 which was consistent with previous studies (Brunborg et al. 2004; Wen et al., 2005; Wang et al., 2009). The result of the present study further confirmed that capsid protein was the major structural protein responsible for viral pathogenecity (Hamel et al., 2000; Mankertz et al., 2000; Larochelle et al., 2002). 

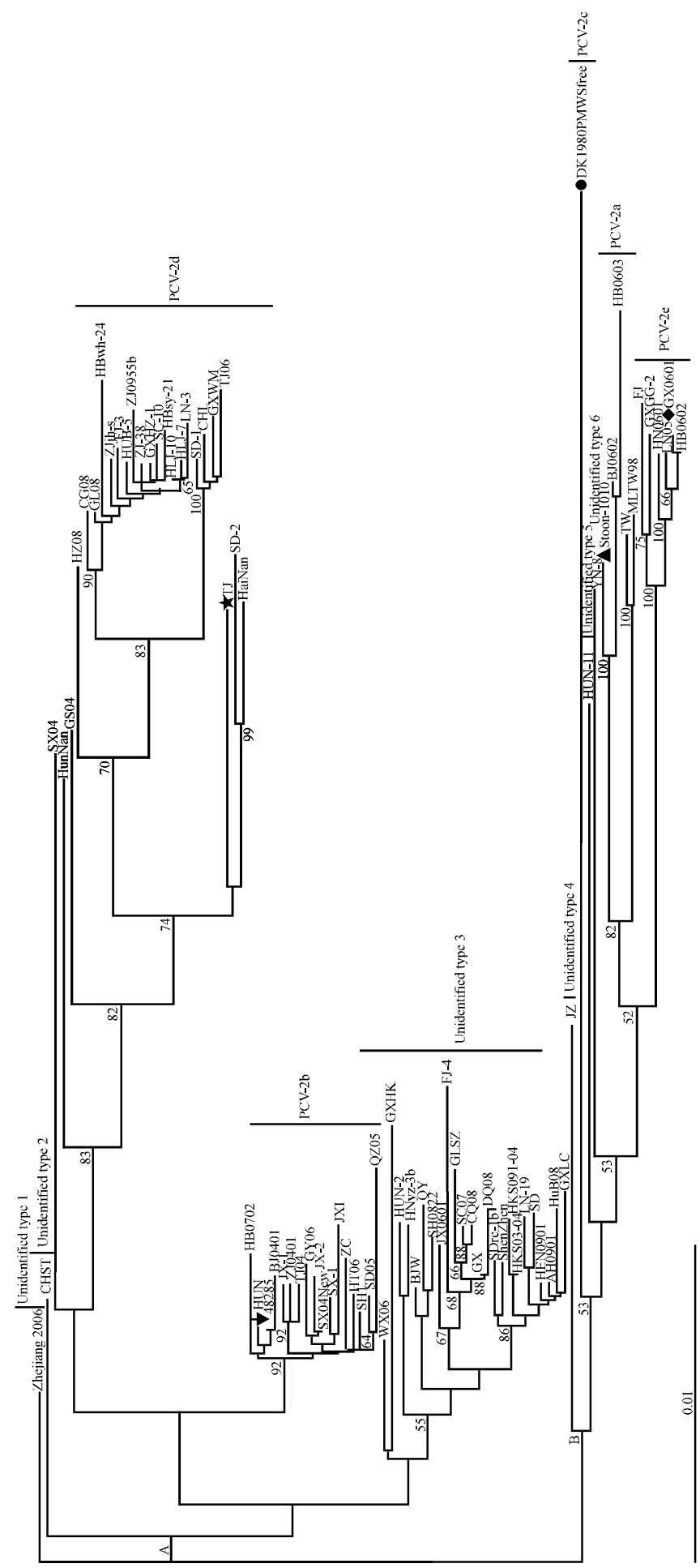

Fig. 2: Phylogenetic analysis of 17 PCV2 strains in this study and 66 strains isolates from other regions of China or other countries based on the complete genomic nucleotide sequences. The tree was constructed using NeighborJoining (NJ) algorithm by MEGA 4.0. ( $\mathbf{\Delta})$ Reference sequences for genotype PCV-2a; $(\boldsymbol{\nabla})$ reference sequences for genotype PCV-2b; $(\bullet)$ reference sequences for genotype PCV-2c; (*) reference sequences for genotype PCV-2d; $($ ) reference sequences for genotype PCV-2e 


\begin{tabular}{ll} 
Table 4: Genotypes of PCV2 in different provinces in China \\
\hline Epidemic \\
province & Genotype \\
Zhejiang & PCV-2b, PCV-2d, unidentified type 1 and 3 \\
Guangxi & PCV-2d, PCV-2e, unidentified type 3 \\
Hebei & PCV-2a, PCV-2b, PCV-2d, PCV-2e, unidentified \\
& type 3 \\
Shandong & PCV-2b, PCV-2d, unidentified type 3 and 4 \\
Tianjin & PCV-2b, PCV-2d \\
Hubei & PCV-2d, unidentified type 3 \\
Shanghai & PCV-2b, PCV-2d, unidentified type 3 \\
Sichuan & PCV-2d, unidentified type 3 \\
Heilongjiang & PCV-2d \\
Liaoning & PCV-2d, PCV-2e, unidentified type 3 \\
Fujian & PCV-2b, PCV-2d, PCV-2e, unidentified type 3 \\
Jiangsu & PCV-2b, PCV-2d \\
Taiwan & PCV-2a \\
Hunan & PCV-2b, PCV-2d, unidentified type 3 and 5 \\
Yunnan & unidentified type 6 \\
Guangdong & PCV-2b, PCV-2d, unidentified type 2 and 3 \\
Beijing & PCV-2a, PCV-2b, unidentified type 3 \\
Henan & PCV-2e, unidentified type 3 \\
Gansu & PCV-2d, unidentified type 3 \\
Chongqing & unidentified type 3 \\
Jiangxi & PCV-2b, unidentified type 3 \\
Shanxi & PCV-2b, PCV-2d \\
Shaanxi & PCV-2b \\
Hainan & Unidentified type 3 \\
Hongkong & \\
&
\end{tabular}

Simultaneously, deduced amino acid sequences alignment obtained mutations in epitopes of $\mathrm{T}$ and $\mathrm{B}$ lymphocytes as previous reports (Larochelle et al., 2002; Wen et al., 2005). Previous studies indicated that the genetic variations of PCV2 might be associated with geographic origin rather than with differences in tropism (Fenaux et al., 2000; Meehan et al., 2001). However, the study showed that the genotypes of PCV2 were not relation to their locations. PCV2 strains from different provinces contained some of the same mutation sites, while strains from the same province have different variations. Phylogenetic tree based on complete genomic sequences also showed that strains from the same provinces were categorized into different genotypes, while same genotypes were in different orgins. The genotypes in the same geographical orgins would be changed with years. These results could be one of the reasons for immunity complexity of PCV2 infection.

\section{CONCLUSION}

The present study examined genetic variations and genotypes of PCV2 strains from 11 epidemic provinces in China in 2008 and 2009 based on complete genomic sequence. Analyses of these sequences revealed low level genetic differences of PCV2 strains in China. Phylogenetic relationships analyses showed that there are novel genotypes of PCV2 existed in China. These results would have important implications for the effective prevention and control of PCV2 infection.

\section{ACKNOWLEDGEMENTS}

Project support was provided by the Ministry of Agriculture Program for prevention and monitoring of animal disease (NY200609-03) to DK Chen and the Special Funds for Talents in Northwest $\mathrm{A}$ and $\mathrm{F}$ University to GH Zhao.

\section{REFERENCES}

Allan, G.M. and J.A. Ellis, 2000. Porcine circoviruses: A review. J. Vet. Diagn. Invest., 12: 3-14.

Allan, G.M., F. McNeilly, S. Kennedy, B. Daft and E.G. Clark et al., 1998. Isolation of porcine circoviruslike viruses from pigs with a wasting disease in the USA and Europe. J. Vet. Diagn Invest., 10: 3-10.

Allan, G.M., K.V. Phenix, D. Todd and M.S. McNulty, 1994. Some biological and physico-chemical properties of porcine circovirus. Zentralbl Vet. Med. B., 41: 17-26.

Brunborg, I.M., T. Moldal and C.M. Jonassen, 2004. Quantitation of porcine circovirus type 2 staind from serum/plasma and tissue samples of healthy pigs and pigs with postweaning multisystemic wasting syndrome using a TaqMan-based real-time PCR. J. Virol. Methods, 122: 170-178.

Burland, T.G., 2000. DNASTAR s Lasergene sequence analysis software. Meth. Mol. Biol., 132: 71-91.

Cheung, A.K., 2003. The essential and nonessential transcription units for viral protein synthesis and DNA replication of porcine circovirus type 2 . Virology, 313: 452-459.

Clark, E.G., 1997. Post-weaning multisystemic wasting syndrome. Proc. Am. Assoc. Swine Pract., 28: 499-501.

Ellis, J., L. Hassard, E. Clark, J. Harding and G. Allan et al., 1998. Isolation of circovirus from lesions of pigs with postweaning multisystemic wasting syndrome. Can. Vet. J., 39: 44-51.

Fenaux, M., P.G. Halbur, G. Haqshenas, R. Royer and P. Thomas et al., 2002. Cloned genomic DNA of type 2 porcine circovirus is infectious when injected directly into the liver and lymph nodes of pigs: Characterization of clinical disease, virus distribution and pathologic lesions. J. Virol., 76: 541-551.

Fenaux, M., P.G. Halbur, M. Gill, T.E. Toth and X.J. Meng, 2000. Genetic characterization of type 2 porcine circovirus (PCV-2) from pigs with postweaning multisystemic wasting syndrome in different geographic regions of North America and development of a differential PCR-restriction fragment length polymorphism assay to detect and differentiate between infections with PCV-1 and PCV-2. J. Clin. Microbiol., 38: 2494-2503. 
Fenaux, M., T. Opriessnig, P.G. Halbur and X.J. Meng, 2003. Immunogenicity and pathogenicity of chimeric infectious DNA clones of pathogenic porcine circovirus type 2 (PCV2) and nonpathogenic PCV1 in weaning pigs. J. Virol., 77: 11232-11243.

Hamel, A.L., L.L. Lin, C. Sachvie, E. Grudeski and G.P.S. Nayar, 2000. PCR detection and characterization of type- 2 porcine circovirus. Can. J. Vet. Res., 64: 44-52.

Jiang, Y., H. Shang, H. Xu, X. Ding, L. Zhao, L. Fang and W. Chen, 2010. Detection and genotyping of porcine circovirus in naturally infected pigs by oligomicroarray. Res. Vet. Sci., 89: 133-139.

Ladekjaer-Mikkelsen, A.S., J. Nielsen, T. Storgaard, A. Botner, G. Allan and F. McNeilly, 2001. Transplacental infection with PCV-2 associated with reproductive failure in a gilt. Vet. Rec., 148: 759-760.

Larochelle, R., R. Magar and S. D'Allaire, 2002. Genetic characterization and phylogenetic analysis of porcine circovirus type 2 (PCV2) strains from cases presenting various clinical conditions. Virus Res., 90: 101-112.

Lekcharoensuk, P., I. Morozov, P.S. Paul, N. Thangthumniyom, W. Wajjawalku and X.J. Meng, 2004. Epitope mapping of the major capsid protein of type 2 porcine circovirus (PCV2) by using chimeric PCV1 and PCV2. J. Virol., 78: 8135-8145.

Li, W., X. Wang, T. Ma, Z. Feng, Y. Li and P. Jiang, 2010. Genetic analysis of porcine circovirus type 2 (PCV2) strains staind between 2001 and 2009: Genotype PCV2b predominate in postweaning multisystemic wasting syndrome occurrences in Eastern China. Virus Genes, 40: 244-251.

Liu, C., Y. Wei, C. Zhang, Y. Lu and X. Kong, 2007. Construction and characterization of porcine circovirus type 2 carrying a genetic marker strain. Virus Res., 127: 95-99.

Lukert, P.D., G.F. de Boer, J.L. Dale, P. Keese, M.S. McNulty, J.W. Randers and I. Tisher, 1995. Family Circoviridae. In: Virus Taxonomy, Classification and Nomenclature of Viruses, Murphy, F.A., C.M. Fauquet, D.H.L. Bishop, S.A. Ghabrial and A.W. Jarvis et al. (Eds.). Springer, New York, pp: 166-168.

Ma, C.M., C.C. Hon, T.Y. Lam, V.Y. Li, C.K. Wong, T. de Oliveira and F.C. Leung, 2007. Evidence for recombination in natural populations of porcine circovirus type 2 in Hong Kong and mainland China. J. Gen. Virol., 88: 1733-1737.

Mahe, D., P. Blanchard, C. Truong, C. Arnauld and R. Cariolet et al., 2000. Differential recognition of ORF2 protein from type 1 and type 2 porcine circoviruses and identification of immunorelevant epitopes. J. Gen., 81: 1815-1824.
Mankertz, A., J. Mankertz, K. Wolf and H.J. Buhk, 1998. Identification of a protein essential for replication of porcine circovirus. J. Gen. Virol., 79: 381-384.

Mankertz, A., M. Domingo, J.M. Folch, P. LeCann and A. Jestin et al., 2000. Characterization of PCV-2 isolates from Spain, Germany andFrance. Virus Res., 66: 65-77.

Meehan, B.M., F. McNeilly, D. Todd, S. Kennedy and V.A. Jewhurst et al., 1998. Characterisation of novel circovirus DNAs associated with wasting syndromes in pigs. J. Gen. Virol., 79: 2171-2179.

Meehan, B.M., F. McNeilly, I. McNair, I. Walker, J.A. Ellis, S. Krakowka and G.M. Allan, 2001. Isolation and characterization of porcine circovirus 2 from cases of sow abortion and porcine dermatitis and nephropathy syndrome. Arch. Virol., 146: 835-842.

Morozov, I., T. Sirinarumitr, S.D. Sorden, P.G. Halbur, M.K. Morgan, K.J. Yoon and P.P. Paul, 1998. Detection of a novel strain of porcine circovirus in pigs with postweaning multisystemic wasting syndrome. J. Clin. Microbiol., 36: 2535-2541.

Nawagitgul, P., I. Morozov, S.R. Bolin, P.A. Harms, S.D. Sorden and P.S. Paul, 2000. Open reading frame 2 of porcine circovirus type 2 encodes a major capsid protein. J. Gen. Virol., 81: 2281-2287.

Olvera, A., M. Cortey and J. Segales, 2007. Molecular evolution of porcine circovirus type 2 genomes: Phylogeny and clonality. Virology, 357: 175-185.

Page, R.D., 1996. Tree View: An application to display phylogenetic trees on personal computers. Comput. Appl. Biosci., 12: 357-358.

Rosell, C., J. Segales, J. Plana-Duran, M. Balasch and G.M. Rodriguez-Arrioja et al., 1999. Pathological, immunohistochemical and in situ hybridization studies of natural cases of Postweaning Multisystemic Wasting Syndrome (PMWS) in pigs. J. Comp. Pathol., 120: 59-78.

Segales, J., A. Olvera, L. Grau-Roma, C. Charreyre and H. Nauwynck et al., 2008. PCV-2 genotype definition and nomenclature. Vet. Rec., 162: 867-867.

Segales, J., G.M. Allan and M. Domingo, 2005. Porcine circovirus diseases. Anim. Health Res. Rev., 6: 119-142.

Shang, S.B., Y.L. Jin, X.T. Jiang, J.Y. Zhou and Y. Yan et al., 2007. Fine mapping of antigenic epitopes on capsid proteins of porcine circovirus and antigenic phenotype of porcine circovirus type 2 . Mol. Immunol., 46: 327-334.

Shen, H.G., J.Y. Zhou, X. Zhang, Z.Y. Huang, J.L. He and $Y$. Yan, 2009. Interference of porcine circovirus type2 ORF2 immunogenicity by ORF1 and ORF3 mixed DNA immunizations in mice. Virology, 393: 104-111. 
Shuai, J., W. Wei, X. Li, N. Chen, Z. Zhang, X. Chen and W. Fang, 2007. Genetic characterization of porcine circovirus type 2 (PCV2) from pigs in highseroprevalence areas in Southeastern China. Virus Genes, 35: 619-627.

Stevenson, L.S., D.F. Gilpin, A. Douglas, F. McNeilly, I. McNair, B.M. Adair and G.M. Allan, 2007. $\mathrm{T}$ lymphocyte epitope mapping of porcine circovirus type 2. Viral. Immunol., 20: 389-398.

Tamura, K., J. Dudley, M. Nei and S. Kumar, 2007. MEGA4: Molecular Evolutionary Genetics Analysis (MEGA) software version 4.0. Mol. Biol. Evol., 24: 1596-1599.

Thompson, J.D., T.J. Gibson, F. Plewniak, F. Jeanmougin and D.G. Higgins, 1997. The clustal X windows interface: Flexible strategies for multiple sequence alignment aided by quality analysis tools. Nucl. Acids Res., 25: 4876-4882.
Wang, F., X. Guo, X. Ge, Z. Wang, Y. Chen, Z. Cha and H. Yang, 2009. Genetic variation analysis of Chinese strains of porcine circovirus type 2. Virus Res., 145: 151-156.

Wen, L., X. Guo and H. Yang, 2005. Genotyping of porcine circovirus type 2 from a variety of clinical conditions in China. Vet. Microbiol., 101: 141-146.

Zhao, G.H., X.H. Mo, F.C. Zou, J. Li and Y.B. Weng et al., 2009a. Genetic variability among Schistosoma japonicum isolates from different endemic regions in China revealed by sequences of three mitochondrial DNA genes. Vet. Parasitol., 162: 67-74.

Zhao, G.H., X.H. Mo, F.C. Zou, J. Li and Y.B. Weng et al., 2009b. Heterogeneity of class I and class II MHC sequences in Schistosoma japonicum from different endemic regions in mainland China. Parasitol. Res., 106: 201-206. 